\title{
The Rise of Islamophobia in the United States: Patterns, Perpetrators, and Reactions
}

\author{
Dr. Navid Ghani \\ Professor of Sociology \\ Hofstra University \\ United States of America
}

\begin{abstract}
This study examines the rise of Islamophobia directed against Muslims in contemporary America society. Why do some people carry out acts of violence against religious minorities and others associated with them? What are the motivations of the perpetrators? And how is their violent behavior influenced by responses from their social environment including media reports and law enforcement agencies? This study looks at a complex set of phenomenon, which has been, described alternatively as racist, violent, anti-immigration and Islamophobic. The study applies mainly qualitative methods such as interviews, secondary literature, direct observations of events, media accounts, and documents from law enforcement agencies such as Federal Bureau of Investigation and the United States Department of Justice. A close study of relevant events and incidents uncovers a variety of organized and unorganized perpetrators, mixed motives, and different types of responses. No single description can explain the hatred against one religious minority group. Neither can one can explain 'why Islamophobia is becoming widespread and entrenched?' or why do some people believe in the ideology of hatred and turn violent against others who are different from them?
\end{abstract}

Keywords: Muslim, Islam, hate crimes, racism, religious beliefs, xenophobia violence, Islamophobia, antiimmigration.

\section{Introduction and background}

With the growing number of immigrants and refugees from Muslim countries as well as terrorist attacks committed by Islamic fundamentalists over the last few years, it is a common argument that antagonism towards Muslims have increased. A new concept has appeared: Islamophobia. It has attracted the attention of academics, social scientists, politicians, and other civil society actors involved. In the United States, the concept of Islamophobia is a widely used in public and scholarly circles today. However, Anti-Semitism, racism, and xenophobic hate crimes are nothing new. During the nineteenth and early twentieth century's, anti-Semitic sentiments and movements against Jews had strong popular support from the United States. As for Japanese Americans, they were forced to relocate and were incarcerated in camps in the interior of the country after the Pearl Harbor attack in 1941, and Japanese phobia was at its peak.

During the post-war period, especially in the 1960's, public discourse in the United States was strongly anti-racist and moralistic. Racism was considered bad for America and the civil rights movement stood against discrimination and hate crimes based on sex, religious beliefs, and gender. However, things started to change when people of color with different norms and values, especially the Muslims, migrated to the United States in the 1970's and 1980's. In the following decades, many more Muslim immigrants and refugees came to the United States as resultof international wars, civil wars or unrest in their home countries. The expanding population of migrants, workers, and refugees emerged as a political and social problem in the United States, reinforcing already growing anti-immigration sentiments. Ekman (2015) argues that social discourse such as "Islam is not compatible with democracy" and that Muslims receive special treatment, such as off from school or job on their religious holidays, clearly indicates an anti-Muslim discourse. Ekman is undoubtedly right about this discourse being principally associated with Muslims; however, this study suggests that the construction of "the Muslim" identity is mainly built around images of Muslim culture and the religion of Islam. Americans started to discover more about Muslims and Islam through events that had an international impact, such as the 9/11 attacks, subsequent terrorist attacks in Madrid and London, the Danish cartoons crisis, and attacks in Brussels, Paris and St. Bernardino in California and so forth. 
These incidents became discursive events that shaped the debates on Islam in the United States and elsewhere. Through these developments the passive image of Muslims transformed into one that was aggressive and violent. The waves of violent acts in recent years specifically at Muslims have caused fear and concern in the United States. Particularly in the election campaign of 2016, the then candidate and now President Donald Trump had frequently played on Islamophobia to increase his popularity. He is the most visible American businessmanturned-politician to capitalize on anti-Muslim sentiment. His call for open profiling and surveillance of Muslims, the Muslim ban from certain Muslim countries - a process that is largely already underway - and claim that "Islamic terrorism" is a biggest threat to the United States can certainly fuel hate-oriented Islamophobia. But what is Islamophobia, exactly? The next section will discuss its definition.

\section{Islamophobia defined}

It is important to conceptualize and define terms early on so that the readers can have a full understanding of the overall analysis and the arguments being made. The following terms are briefly defined to provide context and an understanding forthe discussion on the main term "Islamophobia" used in this study:

Islam: the religious faith of Muslims including belief in God (Allah) as the sole deity and

Muhammad as his prophet.

Muslim: a follower of the religion of Islam.

Radical Islam or Islamism: a set of extreme and violent beliefs resulting from a distortion of the mainstream religion, Islam. Radical Islam and Islam are regarded as two different entities, which are not to be confused with each other.

Researchers and social scientists define Islamophobia as an exaggerated fear, hatred, and hostility toward Islam and Muslims that is perpetuated by negative stereotypes resulting in bias, discrimination, and the marginalization of Muslims (Bleich, 2011). This concept has become a real danger to the foundations of democratic order of the United States. Furthermore, it has also become the main challenge to the social peace and coexistence of different cultures, religions and ethnicities within the country. As a social discourse, Islamophobia is in its infancy and has largely sprung due to the negative attitudes and hatred that have emerged in the post $9 / 11$ contexts. Although its prevalence is difficult to measure, Islamophobia seems most widespread in the United States, as well as to varying degrees in other countries.

\subsection{A conceptual discussion}

The term "Islamophobia" has become well known in academia as much as in the public discourse. Islamophobia operates by creating static 'Muslim' identity, which is attributed in negative terms and generalized for all Muslims. Erik Bleich (2011) describes it as harmful rhetoric and actions directed at Islam and Muslims in Western democracies. According to Bleich, the term not only identifies anti-Islamic and anti-Muslim sentiments, it also provides a language for denouncing them. Similarly, according to Zuquete (2008), Islamophobia is "a widespread mindset and fear-laden discourse in which people make blanket judgments of Islam as the enemy of the west." Thus, Islamophobia is simply another reincarnation of this unfortunate trend of bigotry, resulting in prejudice on the one hand and hatred on the other. According to the British historian Norman Daniel, little has changed since the eleventh century: "The earliest Christian reactions to Islam were something like those of much more recent date. The tradition has been continuous and alive" (Allen, 1980). The term "Islamophobia", he argued, was coined to define this age-old, though growing, hostility against Islam and Muslims. Indeed, as seen in the United States, Islamophobia denotes a range of negative feelings towards Muslims and their religion, Islam, which can manifest in the form of hate crimes, physical and verbal assault, vandalism on mosques, and defamation of Islam in the media. Widely debated even before the 9/11 attacks, this concept of the "Clash of Civilizations" or "Islam vs. West" is based on the premises that there are fundamental differences between Islam and the West, and on the idea that Muslims might be undermining society from within. This notion fueled hostility on the assumption that Muslim culture is incompatible with liberal, democratic and secular American values, and that Muslims therefore do not belong in America. Such rhetoric, however, cannot justify the underlying reasons for anti-Muslim prejudice on the part of mainstream America or elsewhere. Although its prevalence is difficult to measure, the reality is that Islamophobia seems to be most widespread within the American social, political and institutional mechanisms, which produce such hostility towards Muslims and Islam. 
In short, and particularly in the aftermath of November 2016 presidential election, the term Islamophobia has quickly come into general use throughout the United States in political and social discourse and thus made life difficult for American Muslims. This will be discussed in greater depth in the sections below. But first, the methodological approach for this study will be examined.

\section{Methodology}

This study applies mainly qualitative methods and some simple data on hate crimes and acts of violence based on a variety of sources, such as interviews, literature and publications, media accounts, direct observation of events, and documents. Interviews with persons who have some knowledge of hate crimes based on religious beliefs were face-to-face brief conversations and conducted in the spring 2017. As there are only few interviews, the material therefore does not provide a basis for deeper analysis of the interviewee's arguments. Based on my own review of extensive material on hate crime and religious violence, and review of international research into the relationship between the media and terrorism, I highlighted some of the aspects of Islamophobia in the United States through literature and publications. I also have long had a close collaboration with a local Muslim chaplain and community leader, Nayyer Imam, and a Muslim Assistant District Attorney in Brooklyn, New York, Sheharyar Ali, who provided me with highly relevant literature on Islam and the Muslims. Media accounts are an important secondary source on incidents and information about Islamophobia. Readers should be cautious about media reports because such reports sometimes give incorrect information, and tend to exaggerate events.

Direct observation of events, such as demonstrations and rallies in local communities arranged by local community organizations, are also important to examine. Examples of these observations are my participation in the public demonstration on February 19, 2017 in New York in a rally called "Today, I Am a Muslim Too". I also participated in the January 29, 2017 public protest at Battery Park in New York against the executive orders passed by Trump on January 28 to ban Muslim and Muslim refugees from coming to the United States. In both these events, I was a participant as well as an observer. Documents from the law enforcement agencies such as Federal Bureau of Investigation (FBI) and the Bureau of Justice Statistics (BJS), a federal government agency belonging to the U. S. Department of Justice and a principal agency of the U.S. Federal Statistical System, provide useful information as well. Hate crimes such as threatening ethnic minorities and their places of worships can have a devastating impact upon the communities where they occur, which is one of the reasons why the investigation of hate crimes that fall under federal jurisdiction. The FBI gathers and publishes hate crime statistics from law enforcement agencies across the country. The Bureau's latest hate crime report was released in 2016and includes information detailing the offenses, victims, offenders, and locations of hate crimes. The 2016 collection marks the 25th anniversary of the Bureau's work in compiling data related to bias-motivated crimes, which began in 1990. Both these agencies publish data regarding statistics gathered from the roughly fifty thousand agencies from all states that comprise the justice system.

\subsection{Limitations of the data}

Statistics and reports from these agencies provide useful data about violence and perpetrators as well as legal and political underreporting responses to crime related to racism and Islamophobia. Consequently, the data available is somewhat limited; one of the reasons is that the local police likely provide numbers voluntarily to the FBI who then compile the statistics for the whole country. The level of underreporting of racist hate crimes is closely related to the affected minority's perception of the police. If they deem the police to be biased, victims are unlikely to report their complaints to the police. Interestingly, a study by Bureau of Justice Statistics reveals a far greater number of hate crimes than what is reported. For example, in 2012, an estimated 60 percent of hate crimes were not reported to police (BJS, 2014). The fact that most victims do not report racist-motivated hate crimes because they don't feel it is important or that police would help. This shows the limits of hate crime reporting, therefore producing a lack of solid data on the problem nationwide.

\section{Theoretical approaches: Why do perpetrators commit hate crimes?}

Although several explanations may be pertinent to hate crime incidents, no existing criminological theory can fully account for the transformation from prejudice to violent or criminal behavior by perpetrators. Perhaps the most common theory that has been used to explain hate crime -at least in part - is the typologies of hate perpetrators developed by Mcdevitt and Bennett (2002). To explain hate crimes using typology research, they argue that the interplay of several different factors, such as social, psychological, and contextual, must be considered, as these contribute to hate crimes. 
Additionally, other important factors for consideration include perpetrators' motives, victims' characteristics, and cultural ideologies about the victims' social groups. According to this typology, these perpetrators of hate crime are characterized as thrill-seeking individuals who act in response to other hate crimes. In other words, they commit hate crimes to protect their neighborhood from perceived outsiders, and are strongly committed to bigotry that they turn hatred into a pattern. Various other researchers have concurred with Mcdevitt and Bennett's findings that perpetrators frequently seek out the excitement of a hate attack (Byers, Crider, \&Biggers, G. K., 1999).Their findings suggest that a large proportion of hate crimes committed by young men without criminal records will be motivated at least partly by an immature urge to seek out thrill and excitement. However, in forming a more comprehensive picture of the types of hate perpetrators, this study also relies on Barbara Perry's (2001) structured action theory of 'making a difference'. In her theory, she concurred with Mcdevitt and Bennett that thrill-seeking perpetrators frequently seek out the excitement of a hate attack, which is a key motivating factor behind violent crimes. But there is more to these attacks than youths simply seeking 'thrills', as they reveal the existence of negative attitudes and stereotypes towards marginalized groups. She argues that such crimes are better understood as the extreme example form of discrimination, which follows from a culture of discrimination and marginalization of people who are somehow 'different'. Those who are deemed to be different are resisted because they are feared. According to her, hate perpetrators can be common individuals, neighbors, public employees, and national political representatives. Such people are fearful of difference and incite hatred or use rhetoric to discriminate against others. The hate crimes against vulnerable groups are used as examples of how an environment of intolerance is being shaped by such negative rhetoric. Powerful quotes such as 'Islamic terrorism' and the 'immigrant threat 'are provided as illustrations of how individuals are given permission to hate others. Perry argues that hate crimes are not an abnormality of current society, but rather a by-product of a society still coping with inequality, difference, fear, and hate. The various forms of discrimination endured by marginalized groups, a product of what Perry terms 'doing difference', can be taken a step further to include more severe acts of prejudice, such as hate violence. Perry uses the phrase 'doing difference' to characterize the way human behavior is shaped and subordination is maintained within the social structures of power and culture. She uses this theory to account for hate crimes and provide an understanding for the ways we can "do difference differently". Proactive strategies can refer to bridge-building efforts and justice through criminal justice system and action against bigotry and violence. She focuses on strategies for social inclusion and restructuring laws to protect the rights of vulnerable and marginalized groups. From both Mcdevitt and Bennett's conception of 'hate perpetrators' and Perry's use of 'doing difference,' we can begin to see violence committed against Muslims and other immigrants as possibly rooted to the perceived bigotry and hatred in a perpetrator's own life, which he or she believes is the fault of such groups. As a result, various minority groups become the scapegoats for the woes felt by dominant members of society. Blaming others for frustration relating to crime and terrorism is amplified, with certain media outlets portraying Muslim and other immigrants as the root cause of society's problem (see section 'the Role of Media'). Therefore, to better explain the determinants of hate crime in this study, I suggest that the typology of hate perpetrators and 'doing deference' are better understood when they are synthesized. The phenomenon of Islamophobia is still recent and will not disappear any time soon. Future research will need to develop clear theoretical models to account for the causation of hate crimes endured by ethnic and religious minorities. The following sections will formulate and explore a more detailed description of hate-motivated behavior, perpetrators of such acts, and responses. The aim is to provide a general overview of trends and patterns of hate violence that are threatening ideals of diversity and democracy while inspiring acts of anti-Muslim violence across the country. A look at the demographic characteristics of Muslims in the United States will be examined in the following section.

\section{Islam and Muslims in the United States}

Despite being an extremely diverse country, with Muslims being the fastest-growing religious group in the country, the United States has nevertheless been influenced by the post 9/11 hysteria and the recent terrorist attacks mentioned earlier in the article. In addition, the growth and regional migration of Muslims - combined with the ongoing impact of the Islamic State in Iraq and Syria (ISIS) and other extremist groups that commit acts of violence in the name of Islam - have brought Muslims and the Islamic faith to the forefront of the political debate in the United States. Yet, many facts about Muslims are not well known, and most Americans admit to knowing little about Islam and Muslims. 


\subsection{Muslim population in the United States}

Recent political debates in the U.S. over Muslim immigration and related issues such as refugee crisis have prompted many to ask how many Muslims actually live in the country. Answering such a question is not easy, in part because the U.S. Census Bureau does not ask questions regarding religion; therefore, there is no official government count of the U.S. Muslim population. The estimated number of Muslims in the United States varies, depending on the sources. The U.S. Census estimates there are 3 to 6 million Muslims living in the country. At the highest estimates, the percentage of Muslims in the United States would represent approximately1 to 2 percent of the population (U.S. Census, 2016). Pew Research Center (PEW) believes the figure is closer to 3.45 million in 2017,making up roughly $1.1 \%$ of the total U.S. population; this statistic reveals an increase of 0.7 percent since2007, due largely to immigration (PEW, 2017). Pew Research Center is a nonpartisan fact tank in Washington D.C. that informs the public about social and political issues. Both PEW and the U.S. Census estimate that their numbers will double by 2050 because of immigration and the high fertility rate among Muslims. In addition, the U.S. Census suggests the U.S. Muslim population will grow faster than the Hindu and Jewish populations in the coming decades, which will make them the second largest religious group in the U.S. by mid- $21^{\text {st }}$ century.

The Muslim population of the United States includes Pakistanis, Indians, Bangladeshis, Turks, Palestinians, Syrians, Kurds, Moroccans, Iranians, Iraqis, Bosnians, Kosovo Albanians, Somalis and Afghans, as well as Americans converts - many of them women who have married Muslim men. Estimates of the African-American Muslim population have ranged from about one-fifth to one-third of the total for all Muslim Americans. However, Pakistan is the country where most U.S. Muslims immigrants were born. It is also noteworthy to mention that the experiences of Muslim immigrants and African-American Muslims in the United States are unique in the sense that while they share a common identity as Muslims, their racial, cultural, and historical contexts differ widely. Muslim immigrants naturally cluster where others from their homelands already live.Many have settled in metropolitan cities within the states of California, New York, Illinois, New Jersey, Indiana, Michigan, Virginia, Texas, Ohio, and Maryland. There are also established communities near state universities, which often have sizable numbers of foreign-born Muslim students and faculty (PEW, 2014). The overall number of mosques in the United States was 100 in the 1970, but immigration of millions of Muslims since then led to hundreds more being built. According to USA Today, the construction of mosques in the United States rose to 2,106 in 2011, and the building boom continues to grow (USA Today, 2012).

\subsection{Socioeconomic status of Muslim Americans}

According to the PEW survey (2014), Muslim Americans generally mirror the U.S. public in education and income levels, with immigrant Muslims slightly more affluent and better educated than native-born Americans. Twenty-four percent of all Muslims and 29 percent of Muslims have college degrees, compared to 25 percent for the U.S. general population. Forty-one percent of all Muslim Americans and 45 percent of immigrant Muslims report annual household income levels of $\$ 50,000$ or higher. This compares to the national average of 44 percent. Immigrant Muslims are well represented among higher-income earners, with 19 percent claiming annual household incomes of $\$ 100,000$ or higher, compared to 16 percent for the Muslim population and17 percent for the U.S. average (PEW, 2014). This is likely due to the strong concentration of Muslims in professional, managerial, and technical fields, especially in information technology, education, medicine, law, the corporate world, and institutions of higher education. The Pew Research Center whose data are widely cited, maintains that immigration and natural population growth gave impetus to the increase, along with the growing financial resources of American Muslims. An early survey of Muslim Americans demographic portrait done by the Pew Research Center in 2011 reveals that many Muslim Americans are highly religious, pray regularly and attend religious services as often as they can. The participation of Muslim men in these religious activities is much higher than Muslim women. This is because attendance at weekly religious service (e.g., prayers on Fridays) is mandatory for men but optional for women. This survey showed that Muslims living in the United States are middle class and mainstream, largely assimilated, happy with their lives and moderate with respect to religion and religious activities. One common trait characterizing Muslim identity is the Five Pillars of Islam, which are the framework of the Muslim life. They are the testimony of faith, prayer, giving zakat (support to the needy), fasting during the month of Ramadan, and the pilgrimage to Makkah once in a lifetime for those who are able and can afford it. Mosques and other cultural and religious institutions become the focus of practicing their faith, establishing a link with their cultural and religious roots. 
These institutions are not only a place of religious activities, but are also -and more importantly - an arena for maintenance of norms and values for Muslims. Various social and cultural activities that bind the Muslims are played out in this context.

\subsection{Anti-Muslim prejudice}

However, it has become more difficult to be Muslim in the United States in recent years, especially during and after the November election of 2016. The Council on American Islamic Relations (CIAR) is the nation's largest Muslim civil rights and advocacy organization based in Washington, and it reports that ignorance toward Islam and Muslims is widespread in the United States, which partially explains the increase in anti-Muslim attacks in recent years. Ibrahim Hooper, a spokesman for the CAIR, said that he believed the anti-Muslim rhetoric that came out of the 2016 presidential campaign was to blame, and that he feared there would be more hate crimes in coming years. "Whenever you have one of the nation's leading public figures in the person of Donald Trump mainstreaming and empowering Islamophobia in the nation, it will be the inevitable result," (CAIR, 2016). Hooper further says that racist, discriminatory activities and Islamophobia are on the rise in the United States, and many hate groups and organizations win sympathy nationwide with "each passing day". The Southern Poverty Law Center (SPLC) is a non-profit organization that supports Muslims and racial preferences and defendants' rights, and advocates against what it consider "Islamophobic hate groups".According to SPLC, many violent groups use communicative interaction to promote their extremist ideologies, and to praise those who commit or advocate acts of violence. The Southern Poverty Law Center has tracked 892hate groups operating in the United States in 2016, while the most dramatic growth was the near tripling of anti-Muslim hate groups from 5 in 2010 to 34 in 2015, and it has seen a further increase to 101 in2016 (SPLC, 2016).Anti-Muslim hate groups and individuals also broadly defame Islam, which they tend to treat as a monolithic and evil religion. These groups generally hold that Islam has no values in common with other cultures, is inferior to the West, and is a violent political ideology rather than a religion. By their rhetoric, they have attempted to establish themselves as the new resistance movement, fighting 'foreign invaders' and present-day political left. For example, people like Robert Spencer, Frank Gaffney, Steven Emerson, and Daniel Pipes speak of 'resistance movement' that will wage a war against the liberal left and its fight against the "Islamization of America." These individuals represent different hate organizations and have been responsible for orchestrating the majority of misinformation about Islam and Muslims in the United States today (C-Span, 2006). Their rhetorical strategies consist of relating themselves to a set of symbols and values which in their original version are held in high esteem by millions of Americans symbols which represent true nationalism directed against immigrants, particularly Muslims, and with a threat of reprisal against the political left. The language of politics and the media also contributed to this perception. Nayyar Imam, a Muslim community leader in New York told me:

We witnessed a sharp jump in anti-Muslim incidents nationwide last year, with that spike in Islamophobia continuing through 2016 and accelerating after the November 8 election. Now is the time for those leaders who are concerned about traditional American values of religious inclusion and tolerance to speak out against Islamophobia and anti-Muslim hate crime.

He further states that, "It's deeply worrying to see hate crimes surge in recent years, hate crimes demand priority attention because of their impact on society. They not only hurt victims, but also weaken the bonds of our society." Sheharyar Ali, a Muslim Assistant District Attorney from Brooklyn, New York seeks to understand the role of Islam in American constitutional history. He wonders how Islam fits into eighteenth-century American model of religious freedom, when religious suspicion and bigotry was common during the founding of America and thereafter - similar to what is seen today. In her book, Thomas Jefferson's Quran: Islam and the Founders, Denise Spellberg argues that politicians like Thomas Jefferson during the founding of the nation believed that American constitution should make room for Islam and the aspect of human rights it represent. Ali argues that contrary to those who defame Islam and Muslims, this enlightened approach of religious liberty might cause these hate groups to rethink what they are saying. The following section is a summary of recent hate attacks against Muslins, based on available statistics and other data on violent acts and perpetrators. Although data are scant, the aim is to establish the extent of the problem, provide a broad overview of trends and patterns of violence.

\section{Islamophobic incidents and developments in the United States}

The story of Texas youth Ahmed Mohamed has become a commonplace exemplification of the deep-rooted realities of Islamophobia in the United States. 
The 14-year-old Muslim teenager who built a digital clock made out ofa pencil case showed it to his school teacher. Thinking it was a fake bomb, his teacher informed the police who promptly arrested the youth. This incident happened on June 27, 2016, and has become an ever-present symbol of the bigotry and suspicion that pervades American society regarding its Muslim population.

This section highlights significant Islamophobic events, their triggers and consequences in the United States in recent years. The aim is to provide an overview of the main patterns of these Islamophobic acts, and the characteristics of the perpetrators. The section will also explore the rather mixed motives behind their actions, an endeavor which will be continued in greater detail in subsequent sections. The discussion of patterns and perpetrators is partly based on available statistics and chronologies on hate crimes or violence in the United States, and partly from my own attempt to compile comparative data on bombings, arson, shootings and similar forms of violence against Muslims and refugees in recent years. Due to the lack of an adequate apparatus to gather information on Islamophobic events, these statistics only attempt to cover a specific part of the tip of the iceberg.

Since 9/11, the American Federal Bureau of Investigation (FBI) and the Justice Department, have compiled and published, statistics on Islamophobic hate crimes, which are based entirely on voluntary reports by the local law enforcement agencies. As a result of systematic underreporting, there remains enormous gap between FBI hate crime data and the reality of the problem for Muslim Americans and other impacted communities. Therefore, it needs to be done more to collect a reasonable comprehensive and reliable data on Islamophobic acts. The thenFBI director, James B. Comey, acknowledged in a speech to the Anti-Defamation League on May 2017 that the bureau needs "to do a better job of tracking and reporting hate crime, to fully understand what is happening in our communities, and how to stop it"(C-SPAN, 2017).

\subsection{Recent surge in Islamopobic incidents in the United States}

The United States has seen a spike in Islamophobic incidents in recent years, with Muslims all over the country falling victim to shootings, personal assaults, harassment, discrimination, and attacks on their houses of worship. The murder of two kind Samaritans for aiding two young women who were facing a barrage of anti-Muslim slurs on a train in Portland, Oregon, is among the latest examples of brazen acts of anti-Islamic hatred. Since the beginning of 2017, five different mosques in Texas, Washington, Florida, and Michigan have all caught aflame, and many of the alleged perpetrators have been charged with arson and hate crimes (Yahoo News, 2017). Additionally, in 2016, members of a small extremist group called The Crusaders plotted a bombing "bloodbath" at a residential housing complex for Somali-Muslim immigrants in Garden City, Kansas. Muslim Advocates believe that heated political rhetoric and anti-Muslim policies have emboldened potential vandals. According to Corey Saylor, the director of the Department to Monitor and Combat Islamophobia at the Council of AmericanIslamic Relations (CAIR), 2016 has been an especially traumatic year for Muslims in America. He said that people who attack American Muslims and their places of worships feel increasingly justified by things such as Donald Trump's proposal to ban all Muslims from entering the United States or his assertion that all of Islam "hates" America (Think Progress, 2017).

\subsection{Different sources - parallel content}

Muslim Americans are grappling with a surge of anti-Islam incidents in recent years across the country, with many hate groups targeting mosques. Most of the incidents are still under investigation, and many constitute hate crimes. Preliminary data from CAIR indicate that 2016 is on track to be the second-worst year on record regarding mosque attacks, and the year 2017 is trailing nearly to the record set by the previous year (CAIR, 2016). The Nation reports that in 2015, 78 mosques were targeted for arson or other forms of vandalism, more than triple the number of mosques targeted in the two years prior (Nation, 2015).

In its annual hates crimes statistics, the Federal Bureau of Investigation (FBI)found that anti-Muslim hate crimes rose by $67 \%$, from 154 incidents in 2014 to 257 in 2015 despite a nationwide drop in hate crimes overall. It was the highest total since 2001, when more than 480 attacks occurred in the aftermath of the September 11 attacks, a staggering $28 \%$ increase from the year before. However, the number dropped in the following years, and has never returned to levels reported before the $9 / 11$ attacks. That number was still several times higher than the pre9/11 levels (figure 1 below). It is also interesting to observe that a spike in such incidents occurs following specific events. For example, in 2015, we found 45 incidents of anti-Muslim crime in the United States in the four weeks following the November 13 Paris terror attack. Just under half of these occurred after December 2, when the San Bernardino terror attack took place. 
Of those, 15 took place in the five days following December 7; when the then presidential candidate Donald Trump proposed to indefinitely ban all Muslims from entering the United States. In contrast, it is also interesting to note that after an initial sharp spike following the 9/11 attacks, there was a drop in hate crimes after President George W. Bush delivered a speech promoting tolerance, solidarity and mutual contact on September 17, 2001. As you can see from the following figure, right after the speech of the hate crime, incidents dropped sharply from 480 in 2001 to 145 in 2002. This supports what Gordon Allport (1954) concluded in his book, The Nature of Prejudice, that meaningful mutual contact with those who are different is crucial for reducing hatred.

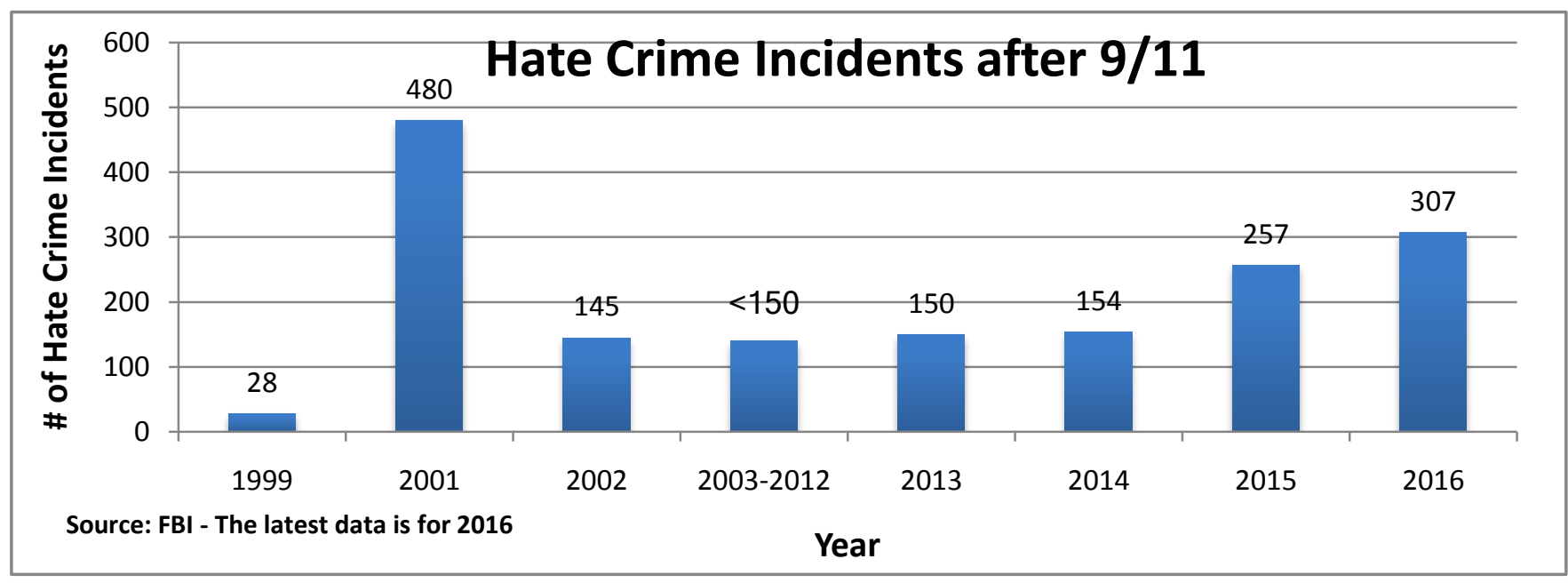

Law enforcement officials acknowledge that the statistics give an incomplete picture, because many local agencies still have a spotty record in reporting hate crimes. Therefore, the data must be interpreted with caution, since unknown number of events may have been missed or gone unreported. The FBI defines a hate crime as a "criminal offense against a person or property motivated in whole or in part by an offender's bias against a race, religion, ethnicity, gender and sexual orientation" (FBI, 2016), whereas the Department of Justice's Bureau of Justice Statistics (BJS) states that an "ordinary crime becomes a hate crime when perpetrators choose a victim because of some characteristics, for example, race, ethnicity, or religion (BJS, 2014). Synthesizing the work of McDevitt et al. (2002) and Perry (2001) discussed earlier, hate crimes typically consist of different factors, such as social, psychological, and contextual, that contributes to hate crime. McDevitt and Bennet (2002) identify that perpetrators are motivated by the "thrill" of their act and the need to enhance their own feelings of power and importance. According to Perry (2001), hate crime is designed to send a message to the victimized community that they are somehow "different" and don't belong" to the wider society". As such, it is a mechanism of power and oppression, intended to reaffirm the role of power dynamic that characterizes a given social order. From this perspective, hate crimes can be seen as verbal abuse through criminal damage, threats, vandalism and act of violence against Muslims and their places of worships. According to the Bureau of Justice Statistics, race is the most common motivation in hate crime, followed by religion and ethnicity (BJS, 2014).

According to Bureau of Justice Statistics, most of the perpetrators are typically men in their late teens and early to mid-twenties who tended to have a low to medium level of education and are predominantly working-class. Most associated with the 2016 presidential elections and look onto Donald Trump as their ideological leader. Trump had heavily focused on minorities, immigrants and Muslims - routinely painting these groups as a threat to economy and national security. Jeb Bush and Ted Cruz, other presidential candidates, had also called for accepting refugees from Syria provided they were Christian, thus effectively banning Muslim Syrian refugees. Yet the fact that only Trump drew widespread outrage shows how accustomed we have become to out-in-theopen anti-Muslim prejudice in this country, and the extremes that now tolerate."In 20 years, I have not heard such intolerance and hatred from political leaders in this society," told Nihad Awad, executive director of the Council on American-Islamic Relations, to the Guardian in November 2015 (Gaurdian, December 2015).According to the Southern Poverty Law Center (SPLC), many violent groups use the Internet to promote their extremist ideologies, and to commend those who commit or advocate acts of violence. The Republicans discourse is adding fire to the xenophobia expressed by far-right groups. This is a serious problem that fuels bigotry and hatred (SPLC, 2016). 


\subsection{Perpetrators and racist violence}

However, there was no firm evidence that these perpetrators were associated with neo-Nazi or racist groups, despite holding apparent racist or Islamophobic views. Although some clusters of violence have been carried out by a single perpetrator or a group of perpetrators as a part of a hate crime, most of these waves do not seem to be coordinated or organized. There is no evidence thus far that large mobs have attacked Muslims and their places of worships. One of the features distinguishing Islamophobic violence from ordinary criminal violence is that perpetrators of such violent acts against Muslims may often find support from other likeminded Americans who are sympathetic to their actions. These actions against Muslims have frequently been preceded by heated debates in the media about terrorism and radical Islam, or issues like Muslim refugees who wished to settle in the United States. Thus, because of the intensive media coverage, perpetrators therefore feel they had a lot of support behind them. In that sense, hate crime may be regarded as an extreme form of an already existing public opinion against Muslims and their religion. The perpetrators could, however, interpret this public opinion as a sign of support that Americans are behind them, unless significant parts of the American population told them otherwise. Interestingly, this has already happened in the form of successful anti-Islamophobic protests and demonstrations, such as "Stop to Islamophobia" and "Defend the Muslim Community" in 2016, and rallies like "I am Muslim Too" in 2017, which gradually spread in the entire country as mentioned and discussed in the previous section.

The following section focuses on the role of the mainstream media's coverage of attack on Muslims and their religion, Islam. Does exposure to media violence increase the tendency towards violent behavior? Although I have tried to address the issue briefly, the question is far too general to be answered in this article.

\section{The role of media}

The previously mentioned polarization of American society can be easily noted in media reporting. After 9/11, and especially in recent years, American social media have increasingly engaged critically with their contribution in spreading negative stereotypes of Muslims and other minority groups. This is especially dramatic because of the important influence the media has over the population's perception. However, as anti-Muslim prejudice is salient in wider society, its narratives are also reflected in news accounts. Popular tropes in this regard allege the incompatibility of Islamic and western values, customs, and lifestyles, as well as the perception that Muslims and Islam cannot be integrated into American society, and doing so will lead to the demise of majority culture. In his book, Reel Bad Arabs: How Hollywood Vilifies a People, Jack Shaheen (2014) found that the vast majority of Arab characters in nine hundred American movies were outright violent and uncivilized characters. Muslim Arabs are portrayed as public enemy number 1, who is brutal, heartless and bent on terrorizing civilized westerners. These Muslim Arabs are shown as incompatible with western values and lifestyle. Images of common day life and ordinary Muslims in their countries are almost non-existent or distorted in the western media. Following the events of 9/11, social media, as well as high-rated TV channels, reproduced such stereotypes by engaging in a debate on cultural explanations for violent attacks on Islam. For instance, Fox News's Bill O'Reilly has declared Islam "as a destructive force and that the United States is in a holy war with certain groups of Muslims" (Fisher, 2015).

\subsection{Stereotyping Sharia Laws}

The most prevalent Islamic stereotype is the development of negative stereotypes in the context of "Sharia Laws", "Jihad", or "Holy War" against the west." This stereotype usually represents violence as an indivisible part of being Islam, as well as presenting religion as justification for violent actions. An example of this kind of stereotype is seen in recent political discourse. President Donald Trump in his election campaign called the religion of Islam as a threat to American values and suggested a ban on Muslims from several countries entry to the United States (Wall Street Journal, 2015).This narrative has been splashed across the front pages of local and national American newspapers throughout the president's election campaign in 2016.

This reflex also resurfaced following the ISIS-inspired attacks in Europe recently. According to the Center for American-Islamic Relations (CAIR), the horrific mass murder in Paris, Belgium and England perpetrated by people claiming affiliation with the militant group ISIS has sparked a widespread backlash against Muslims in the U.S., even though virtually every major Islamic group in the country condemned the attacks (CAIR, 2015).Another contributing factor to this marked rise in Islamophobic hostility is the mass media playing on public fears and spreading misinformation about the federal government's ability to screen Syrian refugees from being resettled into the United States. 
For instance,, in 2016, a former GOP presidential candidate named Ben Carson, repeated a discredited conspiracy theory about "jihad," a fantastical plan about a Muslim plot to take over America in the Mother Jones, a nonprofit news group. When Syrian Muslim refugees became a campaign issue, Carson said, "Bringing in people from the Middle East right now carries extra danger and we cannot put our people at risk because we are trying to be politically correct" (Caldwell, 2016). It is noteworthy that the desire to be noticed by the media and society, and the ensuing status has been central motive for many of the prejudice attacks on Muslims and other minority groups. In the cases of Donald Trump and Ben Carson, they have indeed become popular among millions of Americans, mainly because of the attention their Islamophobic attack aroused in the media. In many cases, the deliberate objective was to gain such attention, and the people involved who make such radical claims were thrilled when the national newspapers and TV news made stories on them and their disliking of Muslims and Islam.

\subsection{Dissemination of fear and violence}

Finally, while journalists and media in general engage increasingly with their possible contribution to reproducing prejudice, anti-Muslim bigoted images and narratives continue to shape media debates. It should be added that no other faith group is treated with inaccurate and often misleading misrepresentation in the national and social media. Granted, it is understandable that local and national media will highlight the issue of Muslims and Islam in their reporting, given the ISIS terror threat we have seen in recent years. However, there is no reasonable excuse for their deceptions and aggravation in their stories. To address the question whether exposure to media dissemination increases the tendency towards violent behavior? The aforementioned political discourse during and after the 2016 presidential elections shows that there is a correlation between exposure to media dissemination and violent behavior, particularly when the issues are related to terrorism and extremism. Many perpetrators of hate violence often act in a political context, with media as a resource to fulfill their objectives. The media often have a direct influence on the actual course of events and their exposure spurs others into action and violence which we have seen in recent years.

\section{Conclusion}

The aim of the study is to establish a robust overview on what is known about Islamophobia, its perpetrators, and responses in the United States. On the basis of this study, it appears that the rise in Islamophobic sentiments since 2001 has become visible in the American public quarter. Perry (2001) and Mcdevitt and Bennett (2002),mentioned in the theoretical concept section, are right when they argue that hate crimes are not an abnormality of current society, but rather a by-product of thrill-seeking individuals whose actions have been described as racist, xenophobic or right-wing extremist acts of violence in a society still coping with inequality, difference, fear, and hate. Furthermore, stereotyping and the negative portrayal of Muslims in the news media is evident in U.S. newspapers, social media websites, news television shows, the internet, popular television shows, and the discourse of public leaders. Spanning across political party lines, the association of "fear" with "Muslim and their religion, Islam" in American political and social rhetoric, has been a key tool to reinforce Islamophobia. Most people assume that Islamophobia exists. But we know less than we should about its dimensions, intensity, and prevalence. Islamicphobic images are fluid and vary in different contexts, as Islamophobia reveals more about the Islamophobic than about the religion itself and its adherents. In part, this is because Islamophobia originated as a political term and is still frequently deployed for political ends. Yet scholars are also using the term increasingly to designate the specific social reality of anti-Islamic and anti-Muslim sentiments in the United States and elsewhere today.

\subsection{The way forward}

Islamophobic hate crimes poses a great risk to the democratic foundations of the United States, as well as the coexistence of various cultures, which make America great. Both the political discourse and the civil society should acknowledge the seriousness of this issue and develop concrete strategies to counter Islamophobia. From the outset, there is a need for more face-to-face contact, interaction, and dialogue between Muslims and the host society so as to remove prejudice, alienation, and marginalization. Allport (1954) points out that social cohesion and integration encourage greater social interaction between different communities, which subsequently leads to strong social bonds and more favorable attitudes towards each other. As the founding fathers said,: When we violate one group's freedom, everyone's liberty is at stake. 
And any attack upon the rights of Christians, Jews, and Muslim citizens should be recognized forwhat it remains: an assault upon the universal ideal of civil rights promised all believers at the country's founding" (Spellberg, 2013).

This approach can be tackled successfully if it is supported by national and bipartisan policies that penetrate into societal perception, public discourse, and the sociopolitical landscape. America needs more courageous politicians who do not only speak out against Islamophobia, but also challenge the politics of right-wing populist ideology. Media personnel such as journalists and editors should also challenge Islamophobia reporting in their news media and give space to more balanced views. Generally, the issue of religious knowledge is a huge problem that does not only concern media and politicians, but also the law enforcement agencies and civil society. We see that people simply lack basic knowledge on Muslims and Islam.

Moez Ahmed, secretary of the Muslim Students Association at Stony Brook University, stated, "Our problem is how to reach an audience outside of interfaith meetings and to convey to them that Islam is a peaceful religion and that the Muslims in the United States are peace loving and law abiding citizens. Ahmed further points out that misinformation about Islam was a factor in influencing people to develop Islamophobic views, and that the media created a perception that radicalism in Islam is the norm rather than the exception. Furthermore, Ahmed argues that it is important for people of all faiths, and of no faith, to educate children about respecting people of various religions, and to teach them to respect people who may be different from them.

\subsection{Final remarks}

Finally, in order to keep the true spirit of multicultural America alive, Muslims need to be just as engaged in promoting better relations as America's non-Muslims. At the same time, Muslims must be allowed to enjoy their spaces of freedom like other dominant religious and political groups without being securitized or criminalized for their beliefs. We hope that general tolerance in political and social discourse will continue in the future and will encourage efforts between American Muslims, as well as non-Muslims, to foster more understanding, tolerance, and unity. Efforts such as these not only help to diffuse hate crimes, but also preserve America's pluralistic and democratic values where people of any faith and ethnic background can enjoy peace and prosperity.

\section{References}

Allport, G.W. (1954). The nature of prejudice. Reading, MA: Addison-Wesley.

Allen, C. (2001). Islamophobia in the media since September $11^{\text {th }}$. University of Westminster, London. UK.

Bleich, E. (2011). What Is Islamophobia, and how much Is there? Theorizing and measuring an emerging comparative concept.American BehavioralScientist, 55, 1581-1600.

Bureau of Justice Statistics. (2014). "U.S. residents experienced about 293,800 Hate crime victimizations in 2012. Unchanged from 2004." February 20, 2014. Washington, D.C.

Byers, B., Crider, B. W., \&Biggers, G. K. (1999). Bias crime motivation: A study of hatecrime offender neutralization techniques used against the Amish. Journal of Contemporary Criminal Justice, 15 (1), 7896.

Caldwell, P. (2016). Ben Carson says Islam is not a religion but a life organization system. Mother Jones. January 29, 2016.

CAIR. (2016). Islamophobia and the Trump Team.January17, 2017.Council on American Islamic Relations. Washington, D.C.

CAIR. (2015). Blacklash Against American Muslims After Paris Attack. November 24, 2015.Councilonmerican Islamic Relations. Washington, D.C.

C-SPAN. (2006). Jihad Watch.[Online] Available: http:/ / www.cspan.org/rebertsepencer/January 1, 2006.

C-SPAN. (2017). We need Better Hate Crime tracking. Anti-Defamation League Conference.Washington, D.C. May 8, 2017.

Epstein, R., \& P. Nicholas. (2015). Donald Trump calls for ban on Muslim entry into U.S. Wall Street Journal. December 7, 2015. New York.

Ekman, M. (2015): Online Islamophobia and the politics of fear: Manufacturing the green scare. Journal ofEthnic and racial Studies, 38 (11), 1986, 2002.

Federal Bureau of Investigation. (2016). Hate crimes against Muslims in US surge 67 percent. FBI Statistics [Online] Available: http://wwwfbi.gov/stories/ November 14, 2016. 
Fisher, M. 2015. Nine questions about the "Holy War" that Bill O'Reilly just declared. Vox Media. February 18, 2015.

Gaurdian. (2015). Obama condemned Islamophobia in America. It's time Republicans did too. The Guardian. December 15, 2015.

Grossman, C. (2012). Number of U.S. mosques up 74\% since 2000. USA Today.February 29, 2012.

Jenkins, J. (2017). As anti-Islam incidents rise, Muslim groups take step to prevent arson. Thinkprogress. May 11, 2017.

McDevitt, J., J. Levin, and S. Bennett (2002). Hate crime offenders: An expandedtypology. Journal of Social Issues, 58 (2), 303-317.

Moscowwitz, P. (2016). We can fight back against Trump's Islamophobia. Nation. November 8, 2016. New York.

Perry, B. (2001). In the name of hate: Understanding hate crimes. New York: Routledge.

Pew Research Center. (2017). New Estimates show U.S. Muslim population continues to grow.Besheer Mohammad. January 3, 2018. Washington, D.C.

Pew Research C enter. (2014). American Muslim perspective. Annual Report. September 9, 2011. Washington, D. C.

Pew Research Center. (2011). No signs of growth in alienation or support for extremism. Survey Report. August 30, 2011.Washington, D.C.

Shaheen, J. (2014). Reel bad Arabs: How Hollywood vilifies a People. InterlinkPublishing Group. 2014.

Spellberg A. D. (2013). Quran: Islam and the Founders. Alfred A. Knoff New York. 2013.

Southern Poverty Law Center. (2016). Incident of hateful harassments since Election Day.Hatewatch Staff. November 18, 2016.

Zúquete, J. P. (2008). The European extreme-right and Islam: New directions?

U.S. Bureau of the Census. (2016). America Muslim population. Government Printing Press, Washington, D. C. 